\title{
Direct effect of RFRP-3 microinjection into the lateral ventricle on the hypothalamic kisspeptin neurons in ovariectomized estrogen-primed rats
}

\author{
LUYANG CHENG $^{1 *}$, SONGHE YANG $^{2 *}$, LINA SI $^{3 *}$, MENG WEI $^{3}$, SEN GUO $^{1}$, \\ ZHIHONG CHEN $^{2}$, SHUSONG WANG ${ }^{4}$ and YUEBING QIAO ${ }^{2}$
}

\begin{abstract}
${ }^{1}$ Department of Immunology, ${ }^{2}$ Graduate School, ${ }^{3}$ Department of Human Anatomy, Chengde Medical University, Chengde, Hebei 067000; ${ }^{4}$ Hebei Provincial Key Laboratory of Reproductive Medicine, Family Planning Science and

Technology Research Institute of Hebei Province, Shijiazhuang, Hebei 050000, P.R. China
\end{abstract}

Received December 18, 2019; Accepted September 21, 2021

DOI: 10.3892/etm.2021.10946

\begin{abstract}
RFamide-related peptide-3 (RFRP-3) may be involved in the inhibition of kisspeptin, but there is no direct evidence that RFRP-3 can directly act on kisspeptin neurons. The present study aimed to investigate the role and mechanism of RFRP-3 and kisspeptin in the hypothalamic-pituitary reproductive axis. In order to detect the expression and localization of RFRP-3 and kisspeptin in dorsomedial hypothalamic nucleus, double immunofluorescence method combined with confocal microscopy were performed. RFRP-3 was injected into the lateral ventricle of ovariectomized estrogen primed rats. Blood and brain tissues were collected at 60-, 120-, 240- and 360-min. Serum levels of gonadotropin-releasing hormone, luteinizing hormone and follicle-stimulating hormone were detected by ELISA. Kisspeptin expression in hypothalamus was detected by western blotting. Finally, surface plasmon resonance was used to verify whether RFRP-3 can directly interact with kisspeptin. Confocal images indicated that RFRP-3 and kisspeptin were co-expressed in the same neurons in the hypothalamus of ovariectomized estrogen-primed rats. Serum concentrations of gonadotropin-releasing hormone, luteinizing hormone and follicle-stimulating hormone were demonstrated to be
\end{abstract}

Correspondence to: Professor Yuebing Qiao, Graduate School, Chengde Medical University, Anyuan Road, Shuangqiao, Chengde, Hebei 067000, P.R. China

E-mail: cdmcqyb@126.com

Professor Shusong Wang, Hebei Provincial Key Laboratory of Reproductive Medicine, Family Planning Science and Technology Research Institute of Hebei Province, 480 Heping West Road, Xinhua, Shijiazhuang, Hebei 050000, P.R. China

E-mail:wshsong@sina.com

*Contributed equally

Key words: gonadotropin inhibitory hormone/RFamide-related peptide-3, kisspeptin, hypothalamic-pituitary reproductive axis, luteinizing hormone, follicle-stimulating hormone significantly reduced following microinjection of RFRP-3 into the lateral ventricle for 60, 120, 240 and $360 \mathrm{~min}$ compared with the corresponding saline groups. The expression levels of kisspeptin in hypothalamus were gradually decreased following microinjection of RFRP-3 into the lateral ventricle. In addition, the affinity constant $\left(\mathrm{K}_{\mathrm{D}}\right)$ of RFRP-3 binding to kisspeptin was $6.005 \times 10^{-5} \mathrm{M}$, indicating that RFRP-3 bound directly to kisspeptin in the range of protein-protein binding strength $\left(\mathrm{K}_{\mathrm{D}}, 10^{-3}-10^{-6} \mathrm{M}\right)$. In conclusion, RFRP-3 may regulate the hypothalamic-pituitary reproductive axis by inhibiting the expression of hypothalamic kisspeptin and direct binding.

\section{Introduction}

The hypothalamic-pituitary-gonadal axis is one of the main systems regulating mammalian reproductive function, including in humans (1). Hypothalamic secretion of gonadotropin-releasing hormone $(\mathrm{GnRH})$ can stimulate the anterior pituitary gland to secrete gonadotropin, which can act on the gonads to stimulate the synthesis of steroid hormones, and promote sperm and egg production $(2,3)$. In the early 21 st century, researchers identified two new neuropeptides that could directly regulate the synthesis and secretion of GnRH; gonadotropin-inhibitory hormone (GnIH) was identified in 2000, and was revealed to inhibit the synthesis and secretion of GnRH in the hypothalamus of mammals and birds by acting on its receptor, neuropeptide FF receptor (NPFFR)1 (4). Mammalian RFRP-1 and RFRP-3 are homologs of poultry $\mathrm{GnIH}$, and are key neuropeptides that regulate the reproductive function in vertebrates (5). Whereas kisspeptin is a neuropeptide encoded by the Kissl gene that was revealed to stimulate the synthesis and secretion of GnRH by acting directly on the KISS1 receptor (KISS1R) of GnRH neurons $(6,7)$. Previous studies have shown that these two neuropeptides may act on the reproductive axis via unilateral or bilateral linkage $(8,9)$; however, to the best of our knowledge, the specific mechanism has not been clarified. It has been shown that RFRP-3 (mammalian homolog of GnIH) may be involved in the inhibition of kisspeptin via the calcium or protein kinase C-related signaling pathways (10), but there is currently no direct evidence that RFRP-3 can directly act on kisspeptin neurons. 
The association between RFRP-3 and kisspeptin, as well as their role and mechanism in the hypothalamic-pituitary reproductive axis, were investigated in the present study. An ovariectomized estrogen-primed (OEP) rat model was first established and RFRP-3 was microinjected into the lateral ventricle. Co-localization of RFRP-3 and kisspeptin was assessed using laser confocal microscopy. Direct binding between RFRP-3 and kisspeptin was evaluated using surface plasmon resonance (SPR). The results indicated that there may be a direct interaction between RFRP-3 and kisspeptin neuropeptides in the hypothalamus of OEP rats, providing experimental evidence for the further study of the regulatory mechanism of the neuroendocrine reproductive axis.

\section{Materials and methods}

Animals. A total of 53 specific pathogen-free grade female Sprague Dawley (SD) rats (age, 6-7 weeks; weight, 200 \pm 20 g) were purchased from Beijing Huafukang Biotechnology Co., Ltd. (certificate no. 11401300067446). The rats were fed in a well-ventilated environment, at a constant temperature $\left(22-25^{\circ} \mathrm{C}\right)$, humidity (50-54\%) and a natural 12/12-h light cycle and free access to food and water. All animal experiments were conducted according to the ethical guidelines of Chengde Medical University and were approved by the ethical review board of Chengde Medical University (Chengde, China).

Animal treatment and grouping. The SD rats were fed adaptively for 1 week, then bilateral oophorectomy was performed under sterile conditions, with animals anesthetized with $0.5 \%$ sodium pentobarbital (40 mg/kg). On day 15 following surgery, $17 \beta$-estradiol $(0.005 \mathrm{mg} / \mathrm{kg} /$ day $)$ was subcutaneously injected into the abdomen. After 5 days of continuous injection, the rats $(n=48)$ were randomly divided into four groups: The 60-min group $(n=12)$; the 120 -min group $(n=12)$; the 240 -min group $(n=12)$; and the $360-$ min group $(n=12)$. Each group included a saline control subgroup $(n=6)$ and a RFRP3 subgroup $(n=6)$. Under anesthesia with $0.5 \%$ sodium pentobarbital (40 mg/kg), the RFRP3 subgroups were injected with $2 \mu \mathrm{g} / \mu \mathrm{l}$ freshly prepared RFRP3 (Bachem AG) into the lateral ventricle at a dose of $16 \mu \mathrm{l} / \mathrm{kg}$, while the saline control subgroups were injected with an equal volume of normal saline. At 60, 120, 240 and $360 \mathrm{~min}$ after injection, the rats were anesthetized with an intraperitoneal injection of $0.5 \%$ sodium pentobarbital (40 mg/kg), samples were collected and rats were sacrificed by cervical dislocation. The humane endpoints used to determine when animals should be euthanized were reduced heart and respiration rates. Cardiac and respiratory arrest was observed for 2-3 min to confirm animal death, and this was defined by the lack of spontaneous breathing for 2-3 min, without blink reflex.

Thionine staining. For rats that did not receive lateral ventricle injection $(\mathrm{n}=5)$, after $500 \mathrm{ml} \mathrm{4 \%}$ paraformaldehyde solution was perfused to fix the tissues, the brain tissues were collected. The brain tissues were fixed with $4 \%$ paraformaldehyde for $24 \mathrm{~h}$, then dehydrated in $30 \%$ sucrose solution for $48 \mathrm{~h}$ at $4^{\circ} \mathrm{C}$. The tissues were embedded in paraffin and sliced into continuous $20-\mu \mathrm{m}$ thick sections-. The brain slices were marked in order and stored at $-20^{\circ} \mathrm{C}$ for use. The brain slices with odd numbers were selected for thionine staining. Briefly, at room temperature, the brain sections were successively incubated with $100 \%$ ethanol twice for 3 min each time, $95 \%$ ethanol for $3 \mathrm{~min}, 70 \%$ ethanol for $3 \mathrm{~min}, 50 \%$ ethanol for $3 \mathrm{~min}$, ultrapure water for $2 \mathrm{~min}, 0.25 \%$ thionine solution for $3 \mathrm{~min}$, ultrapure water for $2 \mathrm{sec}, 50 \%$ ethanol for $3 \mathrm{~min}, 70 \%$ ethanol $+1 \%$ acetic acid for $5 \mathrm{sec}$, $95 \%$ ethanol for $3 \mathrm{~min}, 100 \%$ ethanol twice for $3 \mathrm{~min}$ each time and xylene for $5 \mathrm{~min}$. Finally, the sections were mounted and the posterior medial nucleus of the hypothalamus was determined under a light microscope (magnification, $\mathrm{x} 400$ ).

Double immunofluorescence labeling. For double immunofluorescence labeling, rats without lateral ventricle injection $(n=5)$ were used. According to the results from thionine staining, the posterior medial nucleus sections of the hypothalamus were selected. The sections were washed with $0.02 \%$ PBS twice for 10 min each time, blocked with $5 \%$ donkey serum (Beijing Solarbio Science \& Technology Co., Ltd.) for $2 \mathrm{~h}$ at $4^{\circ} \mathrm{C}$, washed with $0.01 \%$ PBS-Tween-20\% (PBST) for $5 \mathrm{~min}$, and then incubated with goat anti-rat RFRP3 (1:25; cat. no. sc-32380) and rabbit anti-rat kisspeptin (1:50; cat. no. sc-15400; subtype of kisspeptin not available; both from Santa Cruz Biotechnology, Inc.) polyclonal antibodies for $48 \mathrm{~h}$ at $4^{\circ} \mathrm{C}$. The sections were washed with $0.01 \%$ PBST, incubated with the Alexa Fluor ${ }^{\circledR}$ 568-labeled donkey anti-goat (cat. no. A11057) and Alexa Fluor 488-labeled donkey anti-rabbit (1:500; cat. no. A21206) secondary antibodies for RFRP-3 and kisspeptin, respectively (both from Thermo Fisher Scientific, Inc.) for $2 \mathrm{~h}$ at $4^{\circ} \mathrm{C}$ in the dark, then washed with $0.01 \%$ PBST again. DAPI (cat. no. BS130A; Biosharp Life Sciences) was added and the samples were incubated for $5 \mathrm{~min}$ at room temperature in the dark. After washing, the sections were mounted and observed with a laser confocal microscope (magnification, x400; TCS SP8X; Leica AG).

ELISA. At 60, 120, 240 and $360 \mathrm{~min}$ after injection with RFRP-3, venous blood was collected from the rats of each group. After centrifugation at $(3,000 \mathrm{xg})$ for $15 \mathrm{~min}$ at $4{ }^{\circ} \mathrm{C}$, the serum was isolated. The concentrations of $\mathrm{GnRH}$, follicle-stimulating hormone (FSH) and luteinizing hormone ( $\mathrm{LH})$ in the rat serum were determined with rat GnRH (cat. no. ml003038; Shanghai Enzyme-linked Biotechnology Co., Ltd.), rat FSH (cat. no. E-EL-R0391C; Elabscience Biotechnology, Inc.) and rat LH ELISA kits (cat. no. E-EL-R0026C; Elabscience Biotechnology, Inc.).

Western blot analysis. The fresh hypothalamic tissues were separated and the total proteins were extracted using RIPA lysis buffer (Beijing Solarbio Science \& Technology Co., Ltd.). The BCA method was used for protein quantification (Beijing Solarbio Science and Technology Co., Ltd.). Proteins were separated via $12 \%$ SDS-PAGE (20 $\mu \mathrm{g}$ per lane) and transferred onto a PVDF membrane (MilliporeSigma). After blocking with $5 \%$ skimmed milk for $2 \mathrm{~h}$ at room temperature, rabbit anti-rat kisspeptin polyclonal (1:50; cat. no. sc-15400; subtype of kisspeptin not available; Santa Cruz Biotechnology, Inc.) and anti-GAPDH antibodies (1:8,000; cat. no. AP0063; Bioworld Technology, Inc.) were added and the membranes were incubated overnight at $4^{\circ} \mathrm{C}$. After washing with $2.5 \%$ TBS-Tween 20 three times, the goat anti-rabbit IgG HRP-conjugated secondary antibody (1:80,000; cat. no. E030120; Beijing Merida Technology Co., Ltd.) was added. After incubation 
A

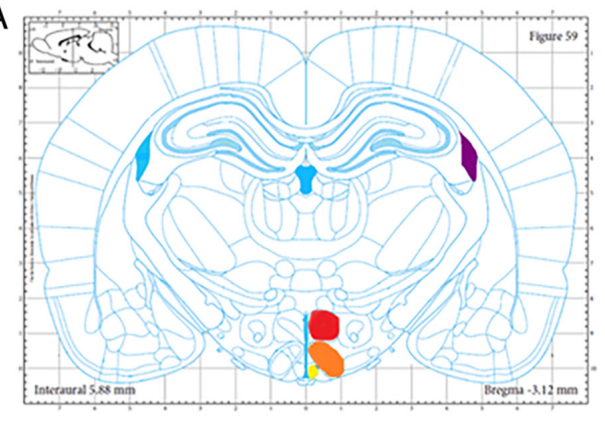

$\mathrm{DMH}=\mathrm{VMH}=\mathrm{ARC}=\mathrm{LV}=$

C

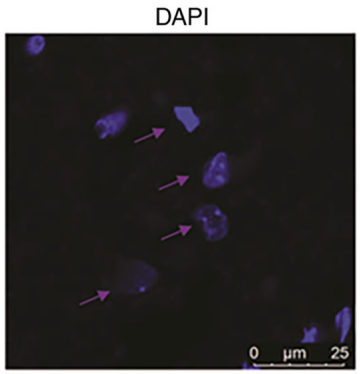

Kisspeptin

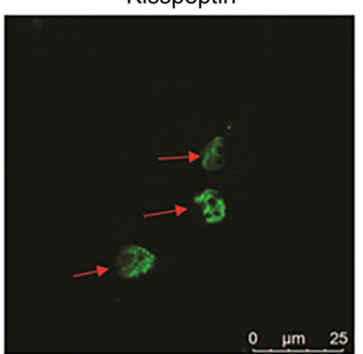

$\mathrm{B}$

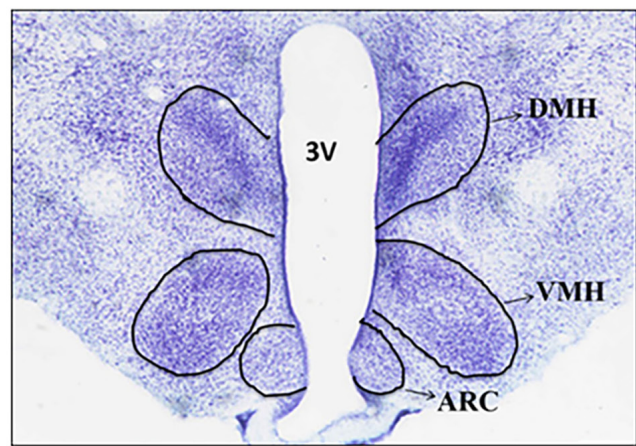

RFRP-3

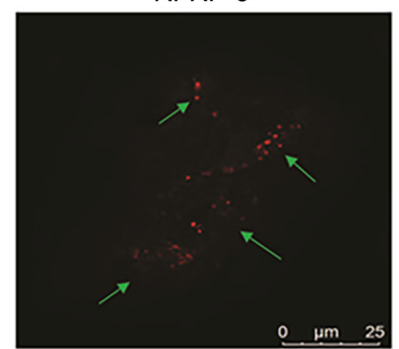

Merged

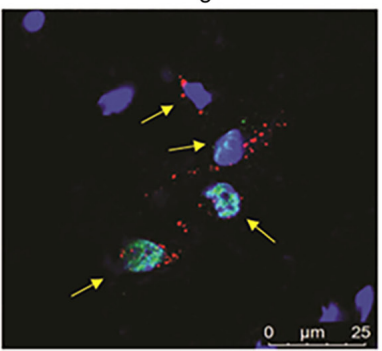

Figure 1. Co-expression of kisspeptin and RFRP-3 in the nerve cells from the hypothalamus (n=5). (A) Brain in stereotaxic coordinates (39). (B) Thionine staining to determine the posterior medial nucleus of the hypothalamus. (C) Double-labelling immunofluorescence to determine the expression of RFRP-3 and kisspeptin. The cell nucleus was stained by DAPI (purple arrows). RFRP-3 was labeled with red fluorescence (green arrows) and kisspeptin was labelled with green fluorescence (red arrows). The yellow arrows indicate the merged cell nuclei. Scale bar, $25 \mu \mathrm{m}$. RFRP-3, RFamide-related peptide-3; DMH, dorsomedial nucleus of the hypothalamus; VMH, ventromedial nucleus of the hypothalamus; ARC, arcuate nucleus; $3 \mathrm{~V}$, third ventricle.

for $1 \mathrm{~h}$ at room temperature, the membrane was washed three times and then analyzed using the Chemiluminescence image analysis kit (Tanon Science \& Technology Co., Ltd.). Image J analysis software (version 1.46r; National Institutes of Health) was used to analyze the average gray value.

SPR. The interaction between kisspeptin and RFRP3 was analyzed using a Biacore T200 SPR system (Cytiva). Kisspeptin (cat. no. CFB170220017; Shanghai Qiang Yao Biotechnology Co., Ltd.) was diluted to $20 \mu \mathrm{g} / \mathrm{ml}$ with sodium acetate buffer (pH 5.5) and coupled to a CM5 sensor chip with a coupling amount of 5,720 response units (RU). PBS-P (10 mM phosphate buffer with $2.7 \mathrm{mM} \mathrm{KCl}, 137 \mathrm{mM} \mathrm{NaCl}$ and $0.05 \%$ surfactant $\mathrm{P} 20, \mathrm{pH} 4.5$ ) was used as the running buffer and RFRP3 (cat. no. H-5846; Bachem AG) was diluted to five concentrations $(3.125,6.25,12.5,25$ and $50 \mu \mathrm{M})$. Different concentrations of RFRP-3 were injected into the detection channel and the reference channel to perform the binding reaction at $4^{\circ} \mathrm{C}$ for $3 \mathrm{~min}$. The experiment was performed by selecting the 'Kinetics' program. The samples were analyzed with an injection time of $60 \mathrm{sec}$, a flow rate of $15 \mu \mathrm{l} / \mathrm{min}$ and a dissociation time of $15 \mathrm{~min}$. After each concentration cycle, the chip was regenerated with glycine- $\mathrm{HCl}(\mathrm{pH} 2.0)$ at a concentration of $10 \mathrm{mM}$ for $30 \mathrm{sec}$. After the end of the cycle, the obtained curve was subjected to data processing using Biacore Evaluation Software (T200 version 2.0; Cytiva) to obtain the kinetic parameters.

Statistical analysis. Data analysis was performed using SPSS v19.0 software (IBM Corp.). The results are presented as the mean \pm standard deviation. Independent-samples t-tests were used to analyze differences between two groups. $\mathrm{P}<0.05$ was considered to indicate a statistically significant difference.

\section{Results}

Kisspeptin and RFRP3 are co-expressed in the nerve cells of the hypothalamus. To observe the localization of kisspeptin and RFRP-3 in the nerve cells of the hypothalamus, thionine staining and immunofluorescence labeling was performed. After thionine staining, the structures of the brain tissues in the rats were observed to be clear and intact with a light blue color. The nerve cells were densely distributed and neatly arranged with clear nucleoli; regions such as the medial dorsomedial nucleus of the hypothalamus (DMH), ventromedial nucleus of the hypothalamus (VMH) and arcuate nucleus (ARC) were clearly visible (Fig. 1A and B). 


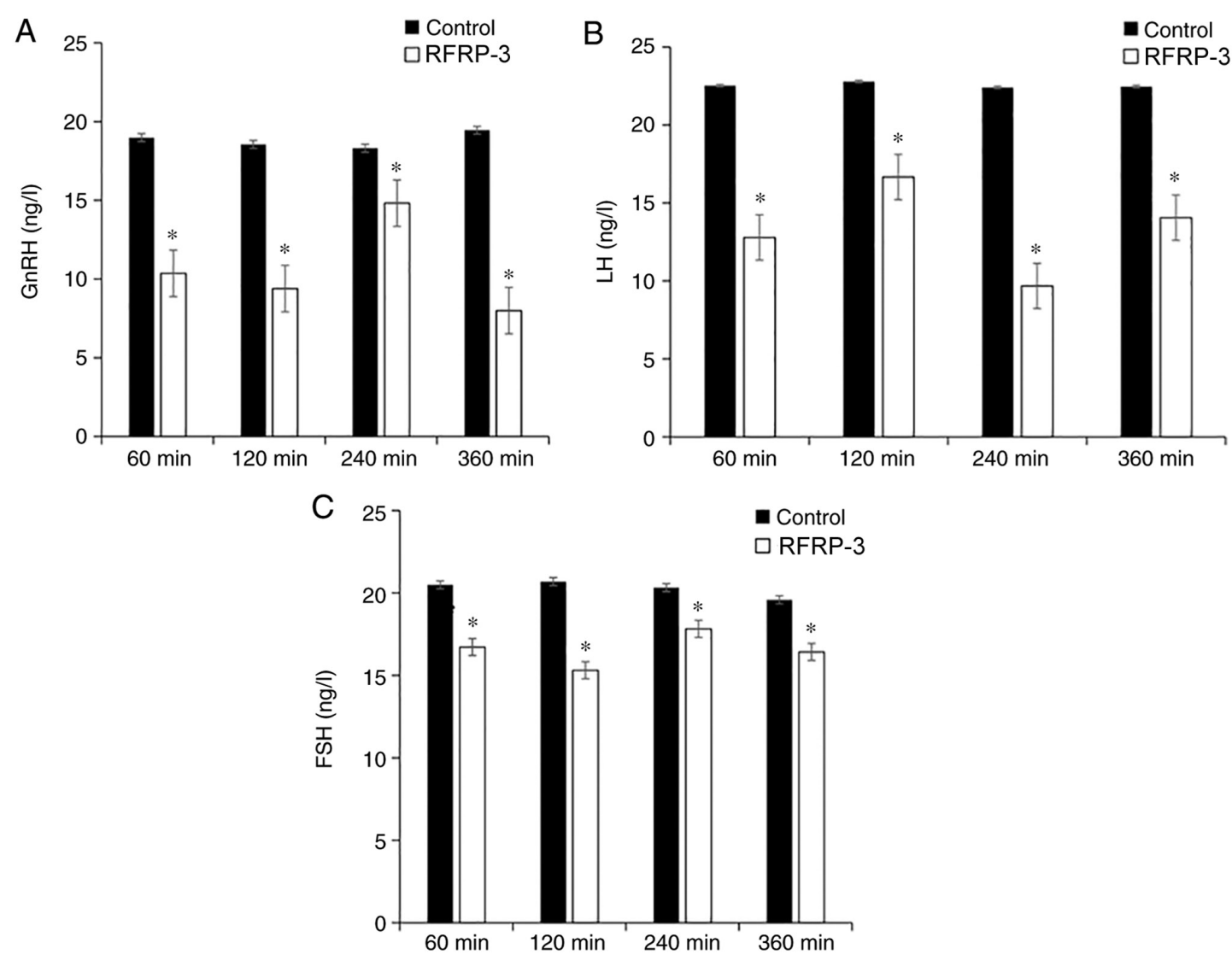

Figure 2. Effects of RFRP-3 on anterior pituitary hormone release $(n=6)$. Effect of intracerebroventricular microinjection of RFRP-3 on the concentration of (A) RFRP-3, (B) LH and (C) FSH in the serum of ovariectomized estrogen-primed rats. "P<0.05 vs. control group. GnRH, gonadotropin-releasing hormone; LH, luteinizing hormone; FSH, follicle-stimulating hormone; RFRP-3, RFamide-related peptide-3.

Double-labeling immunofluorescence was used to determine the expression and localization of RFRP3 and kisspeptin. It was observed that RFRP3 and kisspeptin were co-expressed in the neurons of the hypothalamus, as determined using laser confocal microscopy (Fig. 1C). RFRP3 showed red fluorescence, which was mainly expressed in the cytoplasm of the nerve cells, whereas kisspeptin was labeled green and mainly expressed in the nucleus. In addition, the nuclei were stained with DAPI and showed blue fluorescence. These results indicated that kisspeptin and RFRP-3 were co-expressed in the nerve cells of the hypothalamus.

Reduction of GnRH, LH and FSH in the serum by RFRP3. To determine the concentrations of GnRH, LH and FSH in the serum, ELISA was performed (Fig. 2). The concentration of serum GnRH was $10.36 \pm 1.13,9.39 \pm 1.15,14.82 \pm 1.22$ and $7.99 \pm 1.24 \mathrm{ng} / \mathrm{l}$ at $60,120,240$ and $360 \mathrm{~min}$ after the microinjection of RFRP3 into the lateral ventricle, respectively, while the corresponding $\mathrm{GnRH}$ concentrations in the control groups were $18.98 \pm 0.92,18.55 \pm 0.91,18.31 \pm 0.82$ and $19.45 \pm 1.07 \mathrm{ng} / \mathrm{l}$, respectively. After the injection of RFRP3, the concentrations of GnRH were significantly lower compared with in the control subgroups $(\mathrm{P}<0.05$; Fig. 2A).

The LH concentrations of the RFRP3 groups at the four time points were $12.79 \pm 1.27,16.67 \pm 1.18,9.68 \pm 0.82$ and $14.06 \pm 1.17 \mathrm{ng} / \mathrm{l}$, while those in the control groups were $22.53 \pm 0.99,22.79 \pm 0.76,22.41 \pm 0.99$ and $22.47 \pm 0.94 \mathrm{ng} / 1$, respectively. The concentrations of $\mathrm{LH}$ in the RFRP3 groups were significantly lower compared with in the corresponding control groups $(\mathrm{P}<0.05$; Fig. 2B).

The FSH concentrations of the RFRP3 groups at the four time points were $16.72 \pm 0.67,15.31 \pm 1.12,17.82 \pm 0.74$ and $16.42 \pm 1.04 \mathrm{ng} / \mathrm{l}$, while those in the saline control subgroups were $20.49 \pm 0.68,20.69 \pm 0.75,20.32 \pm 0.95$ and $19.58 \pm 0.85 \mathrm{ng} / \mathrm{l}$, respectively. The concentrations of FSH in the RFRP3 groups were significantly lower compared with in the corresponding control groups $(\mathrm{P}<0.05$; Fig. $2 \mathrm{C})$. These results indicated that microinjection of RFRP-3 into the lateral ventricle inhibited the secretion of GnRH, LH and FSH in the serum of OEP rats, and these three hormones exhibited similar trends at the different time points.

Inhibition of hypothalamic kisspeptin by RFRP3. To demonstrate whether RFRP-3 had a regulatory effect on kisspeptin in the hypothalamus, western blot analysis was performed. The protein expression levels of kisspeptin were presented as the gray value ratio of kisspeptin to GAPDH. At 60, 120, 240 and $360 \mathrm{~min}$ after the microinjection of RFRP3, the protein expression levels of kisspeptin in the hypothalamus of the OEP rats were $115.93 \pm 1.77,103.17 \pm 1.85,86.05 \pm 1.78$ and $67.14 \pm 1.80$, respectively, while those in the corresponding control groups were $134.24 \pm 1.74,135.94 \pm 1.74,131.67 \pm 1.93$ and $125.99 \pm 1.92$, respectively (Fig. 3). The expression levels of kisspeptin in the hypothalamus of OEP rats after the RFRP3 microinjection were significantly different compared with in the control groups $(\mathrm{P}<0.05$; Fig. 3), showing a time-dependent decrease. 
A

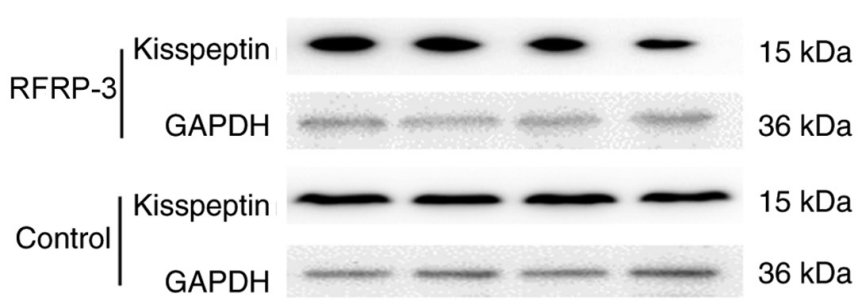

B

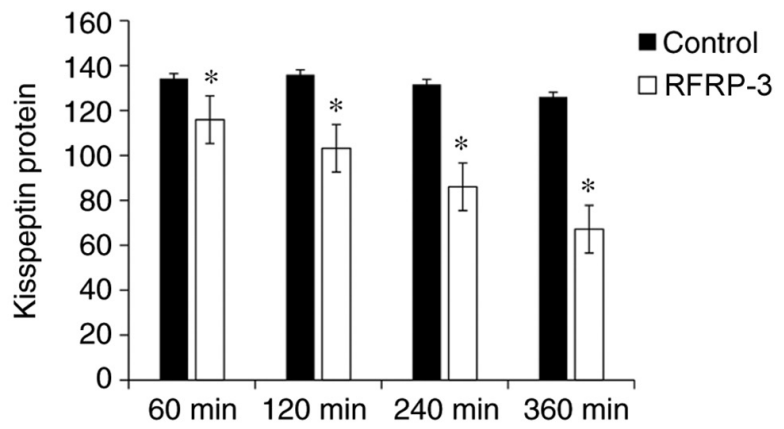

Figure 3. Expression of kisspeptin $(n=6)$. (A) Protein expression levels of kisspeptin after intracerebroventricular microinjection of RFRP3 were detected via western blot analysis. (B) Relative protein expression levels of kisspeptin, as determined by normalizing the gray value of kisspeptin to that of GAPDH. "P<0.05 vs. control group. RFRP-3, RFamide-related peptide-3.

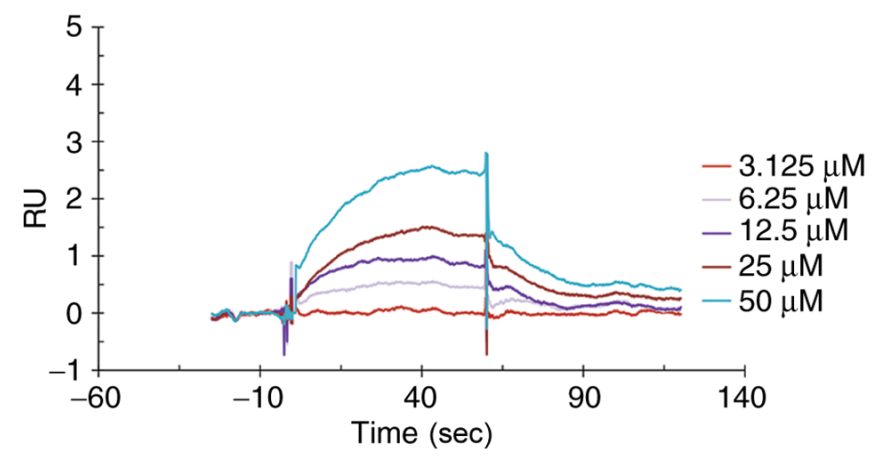

Figure 4. Characterization of the binding affinity between kisspeptin and RFRP3 via surface plasmon resonance. The concentration of kisspeptin was set at $20 \mu \mathrm{g} / \mathrm{ml}$ and different concentrations of RFRP-3 were injected into the detection channel. The binding dissociation curve corresponding to each concentration was recorded and processed using Biacore T200 evaluation software. RFRP-3, RFamide-related peptide-3; RU, response units.

Interaction between RFRP3 and kisspeptin. To demonstrate whether RFRP-3 binds directly to kisspeptin, SPR was performed. The binding dissociation curve corresponding to each concentration is shown in Fig. 4. The obtained curve was subjected to data processing using Biacore T200 evaluation software. The obtained binding rate constant, $\mathrm{K}_{\mathrm{a}}$, was $5.775 \times 10^{3}$ $\mathrm{M}^{-1} \mathrm{sec}^{-1}$, the dissociation rate constant, $\mathrm{K}_{\mathrm{d}}$, was $3.467 \times 10^{-2} \mathrm{sec}^{-1}$ and the affinity constant, $\mathrm{K}_{\mathrm{D}}$, was $6.005 \times 10^{-5} \mathrm{M}$. These results indicated that RFRP-3 could bind directly to kisspeptin.

\section{Discussion}

GnRH is recognized as the only hypothalamic neuropeptide that regulates gonadotropin secretion in vertebrates, which in turn stimulates the secretion of $\mathrm{LH}$ and $\mathrm{FSH}$ from the anterior pituitary $(2,3)$. The present study showed that RFRP-3 could be co-expressed with kisspeptin in the nerve cells of the hypothalamus and that RFRP-3 could directly bind to kisspeptin. Microinjection of RFRP-3 into the lateral ventricle inhibited the concentrations of GnRH, LH and FSH in the serum, and decreased the protein expression levels of kisspeptin in the hypothalamus. In 2000, Tsutsui et al (4) identified a new hypothalamic neuropeptide that could inhibit the secretion of $\mathrm{LH}$ and FSH in the brain of Japanese quail. The sequence of this natural peptide contains 12 amino acids (SIKPSAYLPLRFa), with a RF amide peptide at the carboxy terminus, which was called GnIH (4). Since then, several studies (5,9-18) have found that GnIH is expressed in poultry, fish, amphibians and vertebrate mammals, including humans, and that the structure is highly conserved. Mammalian RFRP-1 and RFRP-3 are homologs of poultry $\mathrm{GnIH}$, and are key neuropeptides that regulate the reproductive function in vertebrates (5). In previous years, numerous studies $(14,19,20)$ have found that GnIH could regulate the feeding behavior of vertebrates, in addition to regulating reproduction. GnIH nerve fibers in sheep could be projected to neuropeptide Y, pro-opiomelanocortin, orexin and melanin-concentrating hormone neurons, which all play important roles in regulating feeding. Anjum et al (21) reported that the administration of $\mathrm{GnIH}$ in mice increased food intake, increased the expression levels of glucose transporter 4 and increased the synthesis of triglycerides in adipose tissue; in addition, GnIH reduced glucose uptake by downregulating the expression levels of glucose transporter 8 and reduced testosterone synthesis, suggesting that $\mathrm{GnIH}$ plays a role in fat accumulation, in addition to negative regulation of testosterone synthesis. Mammalian GnIH neurons are mainly found in the periventricular nucleus $(\mathrm{PeN})$ of the hypothalamus, the DMH, and the area between the DMH and the VMH (22). $\mathrm{GnIH}$ directly inhibits the secretion and release of GnRH via the GnIH receptor, NPFFR1, on the GnRH neurons, thereby inhibiting the synthesis and secretion of gonadotropin $(5,14)$. Since only some GnRH neurons express NPFFR1, GnIH may regulate the $\mathrm{GnRH}$ axis via other interneurons, such as kisspeptin neurons. Studies have shown that RFRP-3 nerve fibers in female mice could be projected onto the anteroventral periventricular nucleus (AVPV) and the PeN of the kisspeptin neurons (23), and GnIH could also bind to NPFFR1 expressed by interneurons, such as the kisspeptin neurons, to inhibit the activity of these neurons, thereby inhibiting the function of the GnRH neurons (5).

Kisspeptin and its receptor, KISS1R, have a stimulating effect on reproductive function (6). Adolescent hypogonadism occurs in humans and rodents lacking functional kisspeptin or the kisspeptin receptor gene, which is characterized by low levels of gonadotropins and sex hormones, hypogonadism and infertility (24-27). Administration of exogenous kisspeptin can effectively promote the secretion of LH and FSH via a GnRH-dependent mechanism (26,28-31). Studies have shown that most GnRH neurons overexpress kisspeptin, and kisspeptin nerve fibers can be projected to GnRH neurons, thus directly activating GnRH neurons $(26,29,32)$. Kisspeptin is a potent stimulator of GnRH release; however, little is known regarding the upstream pathway that regulates the synthesis and secretion of kisspeptin. Kisspeptin is mainly expressed in AVPV, PeN and ARC in the hypothalamus of 
rodents $(28,33)$. Poling et al (34) studied the co-expression of RFRP-3 receptors (NPFFR1 and NPFFR2) in adult male and female hypothalamic kisspeptin neurons. They found that most of the kisspeptin AVPV/PeN neurons did not express RFRP-3 receptors, while some of the ARC kisspeptin neurons expressed the RFRP-3 receptor, suggesting that RFRP-3 may regulate kisspeptin neurons in specific regions of the brain. By contrast, almost all RFRP neurons did not express the kisspeptin receptor and no kisspeptin axon fibers were projected to RFRP-3 neurons, further suggesting that kisspeptin neurons could not directly interact with RFRP-3 neurons (34).

Considering that RFRP-3 could act on kisspeptin neurons to regulate GnRH neurons, it was hypothesized that RFRP-3 is an upstream factor of kisspeptin neurons, which could negatively regulate kisspeptin to inhibit the release of $\mathrm{GnRH}$. There are several types of kisspeptin; however, the specific type of kisspeptin was not distinguished in the present study. Co-expression of RFRP-3 and kisspeptin was found in nerve cells in the hypothalamus of male SD rats using double immunofluorescence labeling, which differs from previous reports that RFRP3 and kisspeptin are expressed in different nerve cells $(5,23,33,34)$. This suggested that RFRP-3 may have a direct effect on kisspeptin in the same nerve cell, which provides a prerequisite for the direct interaction between RFRP-3 and kisspeptin. Since the expression of RFRP-3 was relatively low and the fluorescence brightness was also relatively weak, the co-localized expression was weak. In future studies, how the proteins directly interact will be investigated, for example using co-immunoprecipitation.

To further demonstrate that RFRP3 has a direct regulatory effect on kisspeptin, RFRP3 was microinjected into the lateral ventricle of OEP rats. The results showed that the concentrations of serum GnRH from the OEP rats were significantly decreased after 60, 120, 240 and 360 min following RFRP3 microinjection into the lateral ventricle, in which the serum GnRH concentration at $360 \mathrm{~min}$ was the lowest. As previously described (35), RFRP-3 is released in pulses instead of continuously. Therefore, it was hypothesized that the change in GnRH concentration was associated with the time-dependent effect of RFRPRFRP-3. The LH and FSH concentrations of each RFRP3 group were also reduced compared with in the control group. These results demonstrated that RFRP3 was successfully injected into the lateral ventricle and inhibited gonadotropin secretion. RFRP3 also inhibited the protein expression levels of kisspeptin in the hypothalamus. The distribution and expression patterns of RFRP-3 nerve fibers and their receptors suggested that RFRP-3 may directly act at the pituitary level. A previous study has shown that RFRP-3 could inhibit the secretion of GnRH via its receptor on GnRH neurons, thus acting on the pituitary system to inhibit the expression and secretion of gonadotropin, $\mathrm{LH}$ and FSH (36). The experimental results in the present study also confirmed this statement. As kisspeptin has a positive regulatory effect on GnRH, and the microinjection of RFRP-3 into the lateral ventricle inhibited the secretion of $\mathrm{GnRH}$, it is hypothesized that RFRP-3 may indirectly inhibit the secretion of $\mathrm{GnRH}$ via the intermediate link of kisspeptin, thereby inhibiting reproductive function.

As RFRP-3 and kisspeptin can be co-expressed in the same nerve cells in the hypothalamus of SD rats, the possibility that the two proteins could directly interact to exert their regulatory effects cannot be excluded. To verify this hypothesis, SPR was performed to detect the binding between the recombinant rat RFRP-3 and the kisspeptin proteins $(37,38)$. RFRP-3 showed a binding and dissociation process with kisspeptin, which could be analyzed by kinetic methods. A small affinity value, indicating strong binding between these two proteins, was observed with binding rate, dissociation rate and affinity constants of $5.775 \times 10^{3}$ $\mathrm{M}^{-1} \mathrm{~s}^{-1}, 3.467 \times 10^{-2} \mathrm{~s}^{-1}$ and $6.005 \times 10^{-5} \mathrm{M}$, respectively. The affinity of RFRP-3 to kisspeptin was in the range of protein-protein binding strength $\left(\mathrm{K}_{\mathrm{D}}, 10^{-3}-10^{-6} \mathrm{M}\right)$, indicating that there may be a specific direct binding between the two proteins. Kisspeptin expression was higher in the nucleus, whereas RFRP-3 expression was higher in the cytoplasm. In the preliminary experiments, single staining for kisspeptin was performed and the results showed that there was kisspeptin expression in the cytoplasm. The SPR results showed direct interaction between RFRP-3 and kisspeptin; however, further experiments will be performed to indicate how they interact.

In conclusion, the present study demonstrated that RFRP-3 could co-express with kisspeptin in nerve cells in the hypothalamus, and RFRP-3 could directly bind to kisspeptin. RFRP-3 may regulate the hypothalamic-pituitary reproductive axis by inhibiting the expression of the hypothalamic kisspeptin protein. However, the factors affecting neuronal secretion of RFRP-3 or kisspeptin require further research. The present study provides evidence for further understanding the regulatory mechanism of RFRP-3 and kisspeptin in reproductive function and provides potential targets for the treatment of reproductive dysfunction, which could aid in exploring regulation of reproduction.

\section{Acknowledgements}

The authors would like to thank Ms Lei Chen (Graduate School, Chengde Medical University, Chengde, China) and Ms Xiaochao Liu (Graduate School, Chengde Medical University, Chengde, China) for their assistance with performing animal treatments.

\section{Funding}

The present study was supported by the open project of Key Laboratory of Family Planning and Eugenics of National Health and Family Planning Commission (grant no. 201502), the Natural Science Foundation of Hebei Province (grant no. H2013406115), the Plan Project of Hebei Provincial Science and Technology Department (grant no. 08276101D-20) and the Hebei Higher Education Research Project (grant no. QN2015121).

\section{Availability of data and materials}

The datasets used and/or analyzed during the current study are available from the corresponding author on reasonable request.

\section{Authors' contributions}

YQ and SW conceived and designed the study, and funded and supervised the study. LC, SY and LS performed the experiments, collected and analyzed data, and drafted the manuscript. MW, SG, and ZC participated performing experiments/acquiring data and manuscript revision. LC, SY and LS 
confirmed the authenticity of all the raw data. All authors have read and approved the final manuscript.

\section{Ethics approval and consent to participate}

The present study was approved by the Ethical Review Board of Chengde Medical University.

\section{Patient consent for publication}

Not applicable.

\section{Competing interests}

The authors declare that they have no competing interests.

\section{References}

1. Iwasa T, Matsuzaki T, Yano K, Mayila Y and Irahara M: The roles of kisspeptin and gonadotropin inhibitory hormone in stress-induced reproductive disorders. Endocr J 65: 133-140, 2018

2. Burgus R, Butcher M, Amoss M, Ling N, Monahan M, Rivier J, Fellows R, Blackwell R, Vale W and Guillemin R: Primary structure of the ovine hypothalamic luteinizing hormone-releasing factor (LRF) (LH-hypothalamus-LRF-gas chromatography-mass spectrometry-decapeptide-Edman degradation). Proc Natl Acad Sci USA 69: 278-282, 1972.

3. Matsuo H, Baba Y, Nair RM, Arimura A and Schally AV: Structure of the porcine LH- and FSH-releasing hormone. I. The proposed amino acid sequence. Biochem Biophys Res Commun 43: 1334, 1971.

4. Tsutsui K, Saigoh E, Ukena K, Teranishi H, Fujisawa Y, Kikuchi M, Ishii S and Sharp PJ: A novel avian hypothalamic peptide inhibiting gonadotropin release. Biochem Biophys Res Commun 275: 661-667, 2000.

5. Tsutsui $\mathrm{K}$ and Ubuka T: GnIH control of feeding and reproductive behaviors. Front Endocrinol (Lausanne) 7: 170, 2016.

6. Roa J, Navarro VM and Tena-Sempere M: Kisspeptins in reproductive biology: Consensus knowledge and recent developments. Biol Reprod 85: 650-660, 2011

7. Terasaka T, Otsuka F, Tsukamoto N, Nakamura E, Inagaki K, Toma K, Ogura-Ochi K, Glidewell-Kenney C, Lawson MA and Makino $\mathrm{H}$ : Mutual interaction of kisspeptin, estrogen and bone morphogenetic protein-4 activity in GnRH regulation by GT1-7 cells. Mol Cell Endocrinol 381: 8-15, 2013.

8. Leon S and Tena-Sempere M: Dissecting the roles of gonadotropin-inhibitory hormone in mammals: Studies using pharmacological tools and genetically modified mouse models. Front Endocrinol (Lausanne) 6: 189, 2015.

9. Talbi R, Laran-Chich MP, Magoul R, El Ouezzani S and Simonneaux V: Kisspeptin and RFRP-3 differentially regulate food intake and metabolic neuropeptides in the female desert jerboa. Sci Rep 6: 36057, 2016.

10. Son YL, Ubuka T and Tsutsui K: Molecular mechanisms of gonadotropin-inhibitory hormone $(\mathrm{GnIH})$ actions in target cells and regulation of $\mathrm{GnIH}$ expression. Front Endocrinol (Lausanne) 10: 110, 2019

11. Kriegsfeld LJ, Mei DF, Bentley GE, Ubuka T, Mason AO, Inoue K, Ukena K, Tsutsui $\mathrm{K}$ and Silver R: Identification and characterization of a gonadotropin-inhibitory system in the brains of mammals. Proc Natl Acad Sci USA 103: 2410-2415, 2006.

12. Ubuka T, Son YL and Tsutsui K: Molecular, cellular, morphological, physiological and behavioral aspects of gonadotropin-inhibitory hormone. Gen Comp Endocrinol 227: 27-50, 2016.

13. Tsutsui K: How to contribute to the progress of neuroendocrinology: New insights from discovering novel neuropeptides and neurosteroids regulating pituitary and brain functions. Gen Comp Endocrinol 227: 3-15, 2016.

14. Tsutsui K, Ubuka T, You LS, Bentley GE and Kriegsfeld LJ: Contribution of $\mathrm{GnIH}$ research to the progress of reproductive neuroendocrinology. Front Endocrinol (Lausanne) 6: 179, 2015.
15. Tsutsui $\mathrm{K}$ and Ukena K: Hypothalamic LPXRF-amide peptides in vertebrates: Identification, localization and hypophysiotropic activity. Peptides 27: 1121-1129, 2006

16. Ubuka T, Morgan K, Pawson AJ, Osugi T, Chowdhury VS, Minakata H, Tsutsui K, Millar RP and Bentley GE: Identification of human GnIH homologs, RFRP-1 and RFRP-3, and the cognate receptor, GPR147 in the human hypothalamic pituitary axis. PLoS One 4: e8400, 2009.

17. Ukena $\mathrm{K}$, Iwakoshi $\mathrm{E}$, Minakata $\mathrm{H}$ and Tsutsui $\mathrm{K}$ : A novel rat hypothalamic RFamide-related peptide identified by immunoaffinity chromatography and mass spectrometry. FEBS Lett 512: 255-258, 2002.

18. Ukena $\mathrm{K}$ and Tsutsui $\mathrm{K}$ : A new member of the hypothalamic RF-amide peptide family, LPXRF-amide peptides: Structure, localization, and function. Mass Spectrom Rev 24: 469-486, 2005.

19. Clarke IJ, Smith JT, Henry BA, Oldfield BJ, Stefanidis A, Millar RP, Sari IP, Chng K, Fabre-Nys C, Caraty A, et al: Gonadotropin-inhibitory hormone is a hypothalamic peptide that provides a molecular switch between reproduction and feeding. Neuroendocrinology 95: 305-316, 2012.

20. Kriegsfeld LJ, Ubuka T, Bentley GE and Tsutsui K: Seasonal control of gonadotropin-inhibitory hormone $(\mathrm{GnIH})$ in birds and mammals. Front Neuroendocrinol 37: 65-75, 2015.

21. Anjum S, Krishna A and Tsutsui K: Possible role of GnIH as a mediator between adiposity and impaired testicular function. Front Endocrinol (Lausanne) 7: 6, 2016.

22. Ubuka T, Inoue K, Fukuda Y, Mizuno T, Ukena K, Kriegsfeld LJ and Tsutsui K: Identification, expression, and physiological functions of Siberian hamster gonadotropin-inhibitory hormone. Endocrinology 153: 373-385, 2012.

23. Rizwan MZ, Poling MC, Corr M, Cornes PA, Augustine RA, Quennell JH, Kauffman AS and Anderson GM: RFamide-related peptide-3 receptor gene expression in GnRH and kisspeptin neurons and GnRH-dependent mechanism of action. Endocrinology 153: 3770-3779, 2012.

24. De Roux N, Genin E, Carel JC, Matsuda F, Chaussain JL and Milgrom E: Hypogonadotropic hypogonadism due to loss of function of the KiSS1-derived peptide receptor GPR54. Proc Natl Acad Sci USA 100: 10972-10976, 2003.

25. Funes S, Hedrick JA, Vassileva G, Markowitz L, Abbondanzo S, Golovko A, Yang S, Monsma FJ and Gustafson EL: The KiSS-1 receptor GPR54 is essential for the development of the murine reproductive system. Biochem Biophys Res Commun 312: $1357-1363,2003$

26. Messager S, Chatzidaki EE, Ma D, Hendrick AG, Zahn D, Dixon J, Thresher RR, Malinge I, Lomet D, Carlton MB, et al: Kisspeptin directly stimulates gonadotropin-releasing hormone release via $\mathrm{G}$ protein-coupled receptor 54. Proc Natl Acad Sci USA 102: 1761-1766, 2005.

27. Seminara SB, Messager S, Chatzidaki EE, Thresher RR, Acierno JS Jr, Shagoury JK, Bo-Abbas Y, Kuohung W, Schwinof KM, Hendrick AG, et al: The GPR54 gene as a regulator of puberty. N Engl J Med 349: 1614-1627, 2003

28. Gottsch ML, Cunningham MJ, Smith JT, Popa SM, Acohido BV, Crowley WF, Seminara S, Clifton DK and Steiner RA: A role for kisspeptins in the regulation of gonadotropin secretion in the mouse. Endocrinology 145: 4073-4077, 2004.

29. Irwig MS, Fraley GS, Smith JT, Acohido BV, Popa SM, Cunningham MJ, Gottsch ML, Clifton DK and Steiner RA: Kisspeptin activation of gonadotropin releasing hormone neurons and regulation of KiSS-1 mRNA in the male rat. Neuroendocrinology 80: 264-272, 2004.

30. Kinoshita M, Tsukamura H, Adachi S, Matsui H, Uenoyama Y, Iwata $\mathrm{K}$, Yamada $\mathrm{S}$, Inoue $\mathrm{K}$, Ohtaki $\mathrm{T}$, Matsumoto $\mathrm{H}$ and Maeda K: Involvement of central metastin in the regulation of preovulatory luteinizing hormone surge and estrous cyclicity in female rats. Endocrinology 146: 4431-4436, 2005.

31. Navarro VM, Castellano JM, Fernandez-Fernández R, Tovar S, Roa J, Mayen A, Barreiro ML, Casanueva FF, Aguilar E, Dieguez C, et al: Effects of KiSS-1 peptide, the natural ligand of GPR54, on follicle-stimulating hormone secretion in the rat. Endocrinology 146: 1689-1697, 2005.

32. Yeo SH and Herbison AE: Projections of arcuate nucleus and rostral periventricular kisspeptin neurons in the adult female mouse brain. Endocrinology 152: 2387-2399, 2011.

33. Clarkson J and Herbison AE: Postnatal development of kisspeptin neurons in mouse hypothalamus; sexual dimorphism and projections to gonadotropin-releasing hormone neurons. Endocrinology 147: 5817-5825, 2006. 
34. Poling MC, Quennell JH, Anderson GM and Kauffman AS: Kisspeptin neurones do not directly signal to RFRP-3 neurones but RFRP-3 may directly modulate a subset of hypothalamic kisspeptin cells in mice. J Neuroendocrinol 25: 876-886, 2013.

35. Smith JT, Young IR, Veldhuis JD and Clarke IJ Gonadotropin-inhibitory hormone $(\mathrm{GnIH})$ secretion into the ovine hypophyseal portal system. Endocrinology 153: 3368-3375, 2012.

36. Sari IP, Rao A, Smith JT, Tilbrook AJ and Clarke IJ: Effect of RF-amide-related peptide-3 on luteinizing hormone and follicle-stimulating hormone synthesis and secretion in ovine pituitary gonadotropes. Endocrinology 150: 5549-5556, 2009.

37. Zhao Y, Tong RJ, Xia F and Peng Y: Current status of optical fiber biosensor based on surface plasmon resonance. Biosens Bioelectron 142: 111505, 2019.
38. Xue JJ, Bai Y and Liu HW: Hybrid methods of surface plasmon resonance coupled to mass spectrometry for biomolecular interaction analysis. Anal Bioanal Chem 411: 3721-3729, 2019.

39. Paxinos $G$ and Watson C: The Rat Brain in Stereotaxic Coordinates. 6th edition. Elsevier, Amsterdam, Boston, MA, 2009.

Attribution-NonCommercial-NoDerivatives 4.0 International (CC BY-NC-ND 4.0) License. 